\title{
TAPING THE SONG OF THE GOLDEN-WINGED WARBLER
}

\author{
by Fred G. Bard, Director \\ Saskatchewan Museum of Natural History, Regina
}

Tape recorders have a wide range of uses, but it was quite by accident that I was able to record the unusual Golden-winged Warbler while tape recording bird songs. The story may be of interest to some of our readers.

The Saskatchewan Museum of Natural History has recognized the value of recordings for a good many years and has a fair selection of bird songs. The purpose of gathering the recordings is to add a new dimension to bird study. We began with a MagnaCorder recorder which was an excellent machine for quality, but it was cumbersome for field use. It was operated by two 6-volt car batteries and a converter, all of which had to be carried to the spot; sometimes this was up hill, as when we recorded the Rock Wrens in the Cypress Hills. The MagnaCorder is no longer available and for several years we were without a suitable type of recorder. While there are some excellent ones available, they are very expensive.

The Phillips EL 3302 is battery operated, weighs 3 pounds, 14 ounces, measures $2 \frac{1}{2} \times 6 \frac{1}{2} \times 8$ inches, including the carrying case. Without going into any of the technical details, it is sufficient to say that its size, convenience and quality make it ideal. A meter indicates the battery strength and it takes but a minute to change the five (flashlight) batteries which operate the recorder. Tapes are cassett loaded and offer 60,90 , and 120 minutes of recording time. They are rapidly changed since there is no threading.

The recorder was purchased by the Museum for taking dictation and numerous other chores, since it can be used anywhere. On one of our field excursions, it was tried on bird songs and the quality was found to be quite amazing. As a result, we began collecting a series of bird calls to build a library of natural sounds in specific environments. They were intended for use on Nature Trails in our Parks. The song season of birds is very short -the really good performance is but two to three weeks long at most, when the birds are on territory and filling the daylight hours with their greatest effort and best songs. In the season just ending we got close to 70 recognizable songs of different species. The next job ahead of us is to edit these in such a way as to be of practical value in giving demonstrations. Included in our collection we have, of course, at present a percentage of songs of different birds recognizable to the trained ear, but quite unsatisfactory for teaching purposes.

June 2, 1968, in Regina was a lovely Sunday, warm and bright; the last of the warbler migrants were going through. Having chores to do around the yard provided me with an opportunity to keep my ear in tune with the bird migrants going by, and to rush to the elms in the front of the house to capture whatever sounds of these travellers I could. When taping sounds one becomes aware of the difficulties in capturing nature's sounds when in competition with man-made noises, especially in the city. Our boulevard is practically a speedway; this, coupled with aeroplanes, stop signs and their "roaring getaways", the many sounds of children, barking dogs, power lawn mowers, etc. tries anyone's patience. Well, to get on with the story, the migrants on this day included Clay-colored and Chipping Sparrows, Tennessee and Yellow Warblers, Red-eyed and Warbling Vireos, Least Flycatcher, Eastern and Western Kingbirds. While capturing the songs of these migrants and the ever-present House Sparrows, I became aware of a call that I could not identify. In five hours I was able to record this call 21 different times. Early in 
the evening as the church bells rang, I was able to see the beautiful singer while actually recording its song. It was a male Golden-winged Warbler and visible for at least 30 seconds. The audiospectrogram of the song given on p. 254 of Birds of North America (Robbins, Bruun, Zim and Singer, 1966) is identical with the song I recorded-1 $1 \frac{1}{3}$ seconds duration at a pitch of 4300 to 7500 cycles. Incidentally, on this occasion, I recorded another song which I have not yet been able to identify.

In the fifth edition of the A.O.U. Check-list of North American birds (1957) the breeding range of the Golden-winged Warbler is given as southeastern Manitoba, then eastward and southward in North America. The only other record that we have for Saskatchewan is a sight record by a single observer, Frank Brazier, of a bird seen in Regina on May 18, 1962, and reported in the Blue Jay, 20: 153-4. Being able to record the song of the bird which I had the good fortune to see and hear on June 2, 1968 adds substantially to the evidence of the occurrence of this species in Saskatchewan.

With the tape recorder one is able to identify birds accurately by making recordings of the singer. One can be as accurate in identification as with specimen records, and much more accurate than many records published from hasty sight records. It is known that some birds imitate others, but as mentioned, when a sufficient sample of the song of the individual bird has been taken this method of identification can be positive. Birds sing with various levels of perfection. Tape recorders can capture the sounds of different environments. This is an excellent way to get acquainted with the birds before the spring migration begins, which is always necessary, even to the experienced ornothologist. The more one becomes familiar with sounds the more one realizes their value and the genuine pleasure that can be had from these records. It is much more personal than seeing, and impresses you more. I hope others will take advantage of the facilities that are available in the use of this type of machine. I'm satisfied that it can be of as much pleasure to the amateur as to the professional, and a good deal cheaper than photography -an equally interesting profession. This recorder is adaptable to a variety of uses. When patch cords are used to playback over a high-fi, the quality and volume are again most surprising. This is one of the simplest operating tape recorders, with amazing quality. I highly recommend it.

\section{THE HARLEQUIN DUCK IN SASKATCHEWAN}

\section{by D. F. Brunton, Ottawa, Ontario}

A Harlequin Duck (Histrionicus histrionicus) in the portion of the Prairie Provinces east of the Rockies is a rare occurrence indeed. Godfrey (Birds of Canada, 1966) cites only five records for this area. However, on a birding trip to Regina, Saskatchewan this fall, I was able to add another record to this list.

On a morning trip around Wascana Lake in Regina on September 6, 1968, I spotted three of these small ducks. The Harlequins were flushed from the reeds on the north side of the lake by the Broad Street bridge.
They were exceedingly tame and allowed a close study through $7 \times 50$ binoculars at a distance of approximately 35 feet.

At 1:00 p.m. I returned with $\mathrm{Mr}$. F. Brazier of the Saskatchewan Natural History Society and we again spotted the birds; at this time they were asleep, well out in the open water. Soon after, Mr. F. Bard of the Saskatchewan Museum of Natural History came over and we were able to study them closely, to the point where we were entirely satisfied that they were Harlequin Ducks. I was 